\title{
Öğretmen Adaylarının Ders Çalışma Yaklaşımlarının Akademik Başarıyı Yordama Gücü ${ }^{1}$
}

Hüseyin Hüsnü Bahar²

Muzaffer Okur ${ }^{3}$

Öz

Type/Tür:

Research/Araştırma

Received/Geliş Tarihi: July 23/

23 Temmuz 2018

Accepted/Kabul Tarihi:

September 27/ 27 Eylül 2018

Page numbers/Sayfa No: 307-318

Corresponding

Author/İletişimden Sorumlu

Yazar:mokur@erzincan.edu.tr

\section{$\checkmark$ iThenticate $^{\circ}$}

This paper was checked for plagiarism using iThenticate during the preview process and before publication. / Bu çalışma ön inceleme sürecinde ve yayımlanmadan önce iThenticate yazılımı ile taranmıştır.

\section{Copyright $@ 2018$ by}

Cumhuriyet University, Faculty of Education. All rights reserved.
Ders çalışma yaklaşımı akademik başarıyı etkileyen faktörlerden birisidir. Ders çalışma yaklaşımını yordayan faktörlerin neler olduğu ve ders çalışma yaklaşımının akademik başarıyı ne ölçüde yordadığını ortaya koyan az sayıda çalışma mevcuttur. Bu çalışmada, öğretmen adaylarının cinsiyet ve kayıtlı olunan lisans programına göre ders çalışma yaklaşımları arasında anlamlı fark olup olmadığ 1 ve öğrencinin ders çalışma yaklaşımının akademik başarısının anlamlı bir yordayıcısı olup olmadığı araştırılmıştır. Genel tarama modelinde yürütülen çalışmada veriler eğitim fakültesi programlarına kayıtlı 476 öğrenciden 2017-2018 akademik yılında toplanmıştır. Katılımcıların genel not ortalamaları ve cinsiyetlerine ilişkin bilgileri kişisel bilgi formu ile elde edilmiştir. Derin ve yüzeysel yaklaşım puanlarını belirlemek için Ders Çalışma Yaklaşımları Ölçeği kullanılmıştır. Toplam 20 maddeden oluşan Ders Çalışma Yaklaşımları Ölçeği'nin 10 maddesi derin yaklaşımı, 10 maddesi ise yüzeysel yaklaşımı ölçmeye yöneliktir. Araştırma sorularını cevaplandırmak için faktöriyel ANOVA ile çoklu regresyon analizi tekniği kullanılmıştır. Derin yaklaşım puanlarının bölüm değişkenine göre anlamlı düzeyde farklılaştığı ancak cinsiyet değişkenine göre anlamlı düzeyde farklılaşmadığı gözlenmiştir. Diğer taraftan yüzeysel yaklaşım puanları üzerinde cinsiyet ve kayıtlı olunan program değişkenlerinin anlamlı bir fark oluşturmadığını göstermektedir. Regresyon analizi sonuçları, derin ve yüzeysel yaklaşım puanlarının akademik başarının anlamlı yordayıcıları olduğunu, derin yaklaşım puanlarının genel not ortalamasını pozitif, yüzeysel yaklaşım puanlarının ise negatif yönde yordadığını, genel not ortalamasında gözlenen değişkenliğin \% $10^{\prime}$ unun bu iki değişken tarafından açılandığını göstermektedir.

Anahtar Kelimeler: Ders çalışma yaklaşımı, akademik başarı, derin yaklaşım, yüzeysel yaklaşım, öğretmen adayları

\section{Suggested APA Citation/Önerilen APA Atıf Biçimi:}

Bahar, H. H. ve Okur, M. (2018). Öğretmen adaylarının ders çalışma yaklaşımlarının akademik başarıyı yordama gücü. Cumhuriyet International Journal of Education, 7(3), 307-318 http://dx.doi.org/10.30703/cije.446929

\footnotetext{
${ }^{1} \mathrm{Bu}$ çalışma, "II. International Academic Research Congress (INES 2017)” kongresinde sunulan "Ders çalışma yaklaşımlarının akademik başarıyı yordama gücü " başlıklı sözlü bildirinin genişletilmiş hâlidir.

2 Doç. Dr., Erzincan Binali Yıldırım Üniversitesi, Eğitim Fakültesi, Eğitim Bilimleri Bölümü, Erzincan/Türkiye Assoc. Prof. Dr., Erzincan University, Education Faculty, Department of Education Sciences, Erzincan/Turkey e-mail: hhbahar@erzincan.edu.tr ORCID ID: $\underline{\text { https:// orcid.org/0000-0003-0061-3344 }}$
}

3 Doç. Dr., Erzincan Binali Yıldırım Üniversitesi, Eğitim Fakültesi, Mat. ve Fen Bil.Eğitimi Böl., Erzincan/Türkiye Assoc. Prof. Dr., Erzincan University, Education Faculty, Dep. of Math. and Science Education, Erzincan/Turkey e-mail: mokur@erzincan.edu.tr ORCID ID: $\underline{\text { https://orcid.org/0000-0002-6658-362X }}$ 


\title{
The Predictive Power of Study Approaches on Academic Achievement of Pre-service Teachers
}

\begin{abstract}
The study approach is one of the factors that affect academic achievement. There are few studies that show what factors predict the study approach and how it predicts academic achievement. This study aims to investigate whether there is a significant difference between the study approaches of education faculty students according to their gender and major and whether the student's study approach is a significant predictor of their academic achievement or not. The data of this survey study were collected from 476 students in various departments in the faculty of education during 2017-2018 academic year. The data related to the general achievement scores of the participants and gender were collected using a personal information form. To calculate the deep and superficial approach scores, the Studying Approaches Scale was used. 10 items of the Studying Approaches Scale, which consisted of totally 20 items, were related to measure the deep approach, while 10 were related to superficial aproach. A factorial ANOVA and multiple regression analysis were used to answer the research question. The results show that the departmental variable makes a significant difference on the deep approach scores, whereas gender does not. On the other hand, both gender and program variables recorded on the surface approach scores do not make a significant difference. The results of regression analysis show that the academic achievement of deep approachand surface approach scores are significant predictors. It was also found that the deep approach scores predicted the Studying Approaches Scale positively, and surface approach negatively; $10 \%$ of the variability observed in Studying Approaches Scale were explained by these two variables.
\end{abstract}

Keywords: Study approach, academic achievement, deep approach, superficial approach, pre-service teachers

\section{Giriş}

Üniversitelerin önemli görevlerinden birisi de nitelikli insan gücü yetiştirmektir. Nitelikli insan yetiştirme işi ise ancak öğrenme yoluyla olur. Öğrencinin akademik başarı düzeyi bu öğrenmeleri ne ölçüde gerçekleştirdiğinin bir göstergesi olarak kabul edilebilir. Bandura'nın (1986) sosyal-bilişsel öğrenme kuramına göre öğrenme bilişsel, davranışsal ve çevresel değişkenler arasındaki karşılıklı etkileşimlerin sonucudur. Bilişsel, davranışsal ve çevresel faktörler ise çok sayıda değişken ihtiva eder. Diğer bir ifade ile öğrencinin akademik başarısını etkileyen faktörler çok ve çeşitlidir. İlgili literatürde, öğrenci başarısını etkileyen faktörler ve bu faktörlerin öğrenci başarısına etkisi ile ilgili bazı çalışmalar yapılmıştır (Durmuşçelebi, 2013; Yaşar, 2016). Akbaba'nın (2006) da belirttiği gibi öğrenme, öğrenenden ve öğrenenin bulunduğu ortamdan kaynaklanan çok sayıda faktörden olumlu veya olumsuz yönde etkilenmektedir. Bu kapsamda, öğrenme yaklaşımı da öğrenci başarısını etkileyen faktörlerden birisidir (Biggs, 1999). Öğrencinin kullandığı özel öğrenme yaklaşımı öğrencinin öğrenmesini etkiler (Sæle, Dahl, Sørlie ve Friborg, 2017). Öğrenme görevini öğrencinin ele alma ve öğrenme ortamından etkilenme biçimi, öğrenme çıktıları üzerinde önemli bir etkiye sahiptir (Ekinci, 2009). Öğrenme yaklaşımları, öğrenme amacını ve bu amacı gerçekleştirmek için seçilebilecek aktivitelerdeki farklılıkları ifade etmektedir (Entwistle ve McCune, 2004). Ders çalışan öğrenci çalışma konusunu bütün boyutları ile anlamlandırmaya çalıştı̆̆ı gibi, sadece ezberleme yoluna da başvurabilmektedir (Biggs, 1999). Bazı öğrenciler konuyu tam olarak anlamak amacıyla hareket ederken, diğerleri sadece ders geçme 
amacı ile hareket edebilmektedir (Yılmaz ve Orhan, 2011). Bu kapsamdaki öğrenme yaklaşımları ise derin öğrenme veya yüzeysel öğrenme şeklinde sınıflandırılmaktadır. İlgili kaynaklardaki derin yaklaşım ve yüzeysel yaklaşım ifadeleri de aynı kavramı tanımlamaktadır. Öğrenme etkinliği sırasında kişiler bu yaklaşımlardan birisine göre hareket etmektedir (Y1lmaz ve Orhan, 2011). Derin yaklaşımı benimseyen öğrencinin amacı öğrenmek, yüzeysel yaklaşımı benimseyen öğrencinin amacı ise daha çok dersi geçmek olarak ifade edilebilir.

Öğrenme yaklaşımları ile ilgili olarak yapılan bazı çalışmalarda öğrenme yaklaşımının cinsiyete göre farklılık göstermediği tespit edilmiştir (Ellez ve Sezgin, 2002; Ünal-Çoban ve Ergin, 2008; Sezgin-Selçuk, Çalışkan ve Erol, 2007; Yıldız, 2010; Zhang, 2000). Bununla birlikte bazı çalışmalarda yüzeysel yaklaşım puanlarının erkek öğrencilerde anlamlı ölçüde yüksek olduğu tespit edilmiştir (Çuhadar, Gündüz ve Tanyeri, 2013; Dönmez, Yazıcı ve Demirez, 2016; Ozan, Köse ve Gündoğdu, 2012). Derin öğrenme yaklaşımını kı öğrencilerin daha çok tercih ettiği çalışmaların (Beşoluk ve Önder, 2010; Biggs, 1987; Dönmez vd., 2016; Ozan vd., 2012) yanı sıra erkek öğrencilerin derin öğrenme yaklaşımını daha çok tercih ettiğine ilişkin çalışma sonuçları da mevcuttur (Miller, Finley ve McKinley, 1990).

Yapılan bazı araştırmalarda derin yaklaşımı benimseyen öğrencilerin akademik başarısının daha yüksek olduğu (Akram, Khan, Ameen, Mahmood, Shamim, Amin ve Rana, 2018; Alahdadi ve Ghanizadeh, 2017; Byrne, Flood ve Willis, 2002; Gow, Kember ve Cooper, 1994), öğrencilerin derin yaklaşım puanları ile akademik başarı puanları arasında pozitif, yüzeysel yaklaşım puanları ile akademik başarı puanları arasında negatif yönde ilişki olduğu tespit edilmiştir (Çetin, 2016; Liu, Ye ve Yeung, 2015; Olpak ve Korucu 2014). Üniversite öğrencilerine yönelik olarak yapılan bir çalışmada ise derin öğrenme yaklaşımının akademik başarının olumlu yordayıcısı olduğu tespit edilmiştir (Sæle vd., 2017).

Literatürde, ders çalışma yaklaşımını yordayan faktörlerin neler olduğu ve ders çalışma yaklaşımının akademik başarıyı ne ölçüde yordadığını ortaya koyan az sayıda çalışma mevcuttur. Öğretmen adaylarının ders çalışma yaklaşımlarının hangi değişkenlerden etkilendiği ve akademik başarı üzerindeki etkisinin tespit edilmesinin, öğrenme sürecinin iyi bir şekilde planlanmasına ve uygulama sürecine önemli katkı sağlayacağı düşünülmektedir.

Araştırmanın amacı eğitim fakültesi öğrencilerinin cinsiyet ve kayıtlı olunan lisans programına göre ders çalışma yaklaşımları arasında anlamlı fark olup olmadığını belirlemek ve öğrencinin ders çalışma yaklaşımının akademik başarısının anlamlı bir yordayıcısı olup olmadığını tespit etmektir.

\section{Yöntem}

Genel tarama modelinde yürütülen bu çalışmada veriler bir Eğitim Fakültesinin programlarına kayıtlı 476 öğrenciden 2017-2018 akademik yılında toplanmıştır. Katılımcılara ilişkin frekans ve yüzdeler Tablo 1'de gösterilmiştir. Dört farklı öğretmen yetiştirme programına kayıtlı olan katılımcıların 161'i erkek 315'i ise bayan öğrencilerden oluşmaktadır. 
Tablo 1

Katılımcıların Kayıtı Olduğu Program, Cinsiyete Göre Frekans ve Yüzdeleri

\begin{tabular}{lcc}
\hline Değişken & Frekans & Yüzde \\
\hline Öğrencinin kayıtlı olduğu program & & \\
İlköğretim Matematik Öğretmenliği (IM) & 95 & 20,0 \\
Psikolojik Danışmanlık ve Rehberlik (PDR) & 177 & 37,2 \\
Sınıf Öğretmenliği (SÖ) & 104 & 21,8 \\
Türkçe Öğretmenliği (TÖ) & 100 & 21,0 \\
Cinsiyet & & \\
Erkek & 161 & 33,8 \\
Kadın & 315 & 66,2 \\
Toplam & 476 & 100,0 \\
\hline
\end{tabular}

Katılımcıların Genel Not Ortalamaları (GNO) ve cinsiyete ilişkin bilgileri kişisel bilgi formu ile elde edilmiştir. Derin ve yüzeysel yaklaşım puanlarının belirlemek için Biggs, Kember ve Leung (2001) tarafından geliştirilen ve Türkçe uyarlaması Yılmaz ve Orhan (2011) tarafından yapılan Ders Çalışma Yaklaşımları Ölçeği (DÇYÖ) kullanılmıştır. Toplam 20 maddeden oluşan DÇYÖ'nün 10 maddesi Derin Yaklaşımı (DY), 10 maddesi ise Yüzeysel Yaklaşımı (YY) ölçmeye yöneliktir. Derin ve yüzeysel yaklaşım boyutlarının her birinden katılımcıların alabileceği en düşük puan 10, en yüksek puan ise 50'dir. Ölçek için hesaplanan güvenirlik katsayıları Tablo 2'de gösterilmiştir. Özgün ölçekte (Biggs, Kember ve Leung, 2001) bulunan iç tutarlık katsayıları derin yaklaşım için .73, yüzeysel yaklaşım için .64'tür. Yılmaz ve Orhan (2011) tarafından uyarlanan ölçeğin iç tutarlık katsayıları derin yaklaşım için .79, yüzeysel yaklaşım için .73'tür. Mevcut çalışmada hesaplanan iç tutarlık katsayıları derin yaklaşım için .77, yüzeysel yaklaşım için .78'dir.

Tablo 2

Derin ve Yüzeysel Yaklaşım İçin Hesaplanan İç Tutarlık Katsayıları

\begin{tabular}{ccccc}
\hline Boyutlar & $\begin{array}{c}\text { Madde } \\
\text { Sayıs1 }\end{array}$ & $\begin{array}{c}\text { Cronbach's Alpha } \\
\text { (N: 476) }\end{array}$ & $\begin{array}{c}\text { Cronbach's Alpha } \\
\text { (Yllmaz ve Orhan) N: 400 }\end{array}$ & $\begin{array}{c}\text { Cronbach's Alpha } \\
\text { Özgün Ölçek }\end{array}$ \\
\hline Derin & 10 & .77 & .79 & .73 \\
Yüzeysel & 10 & .78 & .73 & .64 \\
\hline
\end{tabular}

DÇYÖ'nün yapısının mevcut çalışmada doğrulanıp doğrulanmadığını test etmek üzere DFA uygulanmıştır. Oluşturulan modelin uyum değerleri için $\mathrm{X}^{2} / \mathrm{Sd}$, GFI, AGFI, RMSEA indekslerinden yararlanılmıştır. Uyum indeksleri $X^{2} /$ Sd değeri için 2.55; GFI değeri için .91; AGFI değeri için .89; RMSEA değeri için .06 olarak hesaplanmıştır. Elde edilen indeks değerleri oluşturulan modelin uyumlu olduğunu ve dolayısıyla DÇYÖ'́nün çalışmada yer alan örneklem için de kullanılabilir bir ölçek olduğunu ortaya koymaktadır (Karagöz, 2016).

Öğrencilerinin cinsiyet ve kayıtlı olunan öğretmen yetiştirme programına göre ders çalışma yaklaşımları arasında anlamlı fark olup olmadığını belirlemek için faktöriyel ANOVA, ders çalışma yaklaşımının akademik başarısının anlamlı bir yordayıcısı olup olmadığını belirlemek için ise çoklu regresyon analizi yapılmıştır. Bağımsız değişkenlerin her ikisi de modele dâhil edilerek, modelin bağımlı değişkeni 
tahmin etme başarısı ve modelin tahmin etme gücünü önemli derecede artırmayan değişkeni belirlemek amacıyla regresyon analizi yöntemlerinden standart yöntem olan enter metodu kullanılmıştır. Enter metodunda, modeli oluşturan bağımsız değişkenlerin hepsi modele dahil edilerek, modelin bağımlı değişkeni tahmin etme başarısı belirlenir. Her bir bağımsız değişken modelden çıkarılarak, bunların modele katkısı değerlendirilebilir. Değerlendirmede, modelin tahmin etme gücünü önemli derecede artırmayan değişken modelden çıkarılabilir (Karagöz,2016). DY ve YY değişkenleri birlikte modele dâhil edilmiş, her iki bağımsız değişkenin GNO üzerindeki ortak etkisi incelenmiştir.

\section{Bulgular}

Katılımcıların cinsiyet ve kayıtlı olduğu lisans programına göre derin yaklaşım puanlarına ilişkin ANOVA sonuçları Tablo 3 'te gösterilmiştir. Katılımcıların akademik başarı puanları ile derin ve yüzeysel yaklaşım puanlarına ilişkin betimleyici istatistikler Tablo 5'te gösterilmiştir. Katılımcıların başarı not ortalamasının 2.77, derin yaklaşım puan ortalamasının 31.00, yüzeysel yaklaşım puan ortalamasının ise 27.12 olduğu görülmektedir. Analiz sonuçlarına göre, derin yaklaşım puanları üzerinde bölüm değişkeni anlamlı bir fark oluştururken $(F(3,468)=$ $\left.7.97, p<.01, \eta^{2}=.05\right)$, cinsiyet değişkeninin anlamlı bir fark oluşturmadiğ $1(F(1,468)=$ $.80, p>.05)$ tespit edilmiştir. Cohen'in (1988'den Akt. Kilmen, 2015) belirttiği gibi etki büyüklüğü 0.01 ve daha büyük, 0.06 'dan daha küçük ise düşük; 0.06 ve daha büyük, .138'den küçük ise orta; 138 ve daha yüksek ise etki büyüklüğü büyük olarak ifade edilebilir. Bu referans değerlerine göre bölüm değişkeninin derin yaklaşım puanları üzerinde düşük düzeyde bir etkiye sahip olduğu anlaşılmaktadır. Cinsiyet ve kayıtlı olunan lisans programının derin yaklaşım puanları üzerindeki ortak etkisinin anlamlılık sınırında olduğu $\left(F(3,468)=2.62, p=.05, \eta^{2}=.02\right)$, düşük düzeyde bir ortak etkiye sahip olduğu görülmektedir. Tukey testi sonuçları, anlamlı farkın SÖ $(O=34.55)$ programına kayıtlı olan öğrencilerle PDR $(O=29.63)$ ve İM $(O=27.38)$ programlarına kayıtlı olan öğrenciler arasında olduğunu göstermektedir.

Tablo 3

Katılımcların Cinsiyet ve Kayıtlı Olduğu Lisans Programına Göre Derin Yaklaşım Puanlarına İlişkin ANOVA Sonuçları

\begin{tabular}{lcccccc}
\hline Kaynak & Kareler toplam & Sd & $\begin{array}{c}\text { Kareler } \\
\text { ortalaması }\end{array}$ & $\mathrm{F}$ & $\mathrm{p}$ & $\eta 2$ \\
\hline Düzeltilmiş model & $994.96^{\mathrm{a}}$ & 7 & 142.14 & 3.65 & $.00^{*}$ & .05 \\
Kesişim & 365342.18 & 1 & 365342.17 & 9382.64 & $.00^{*}$ & .95 \\
Cinsiyet & 31.19 & 1 & 31.19 & .80 & .37 & .00 \\
Bölüm & 930.54 & 3 & 310.18 & 7.97 & $.00^{*}$ & .05 \\
Cinsiyet * Bölüm & 306.38 & 3 & 102.13 & 2.62 & .05 & .02 \\
Hata & 18223.03 & 468 & 38.94 & & & \\
Toplam & 476530.00 & 476 & & & & \\
Düzeltilmiş & 19217.99 & 475 & & & & \\
Toplam & & & & & &
\end{tabular}

a. $R^{2}=.05$ (Düzeltilmiş $\left.R^{2}=.04\right) \quad{ }^{*} p<.01$ 
Katılımcıların cinsiyet ve kayıtlı olunan lisans programına göre yüzeysel yaklaşım puanlarına ilişkin bağımsız gruplar için faktöriyel ANOVA testi sonuçları Tablo 4'te gösterilmiştir. Test sonuçları, yüzeysel yaklaşım puanları üzerinde cinsiyet $(F(1,468)=1.44, p>.05)$ ve kayitlı olunan program $(F(3,468)=.60, p>.05)$ değişkenlerinin anlamlı bir fark oluşturmadığını göstermektedir.

Tablo 4

Katılımcların Cinsiyet ve Kayıtlı Olduğu Lisans Programına Göre Yüzeysel Yaklaşım Puanlarına İlişkin ANOVA Sonuçları

\begin{tabular}{|c|c|c|c|c|c|c|}
\hline Kaynak & Kareler toplamı & $S d$ & $\begin{array}{c}\text { Kareler } \\
\text { ortalaması }\end{array}$ & $F$ & $p$ & $\eta 2$ \\
\hline Düzeltilmiş model & $377.63 a$ & 7 & 53.94 & 1.03 & .41 & .02 \\
\hline Kesişim & 283716.02 & 1 & 283716.02 & 5437.53 & .00 & .92 \\
\hline Cinsiyet & 75.17 & 1 & 75.17 & 1.44 & .23 & .00 \\
\hline Bölüm & 93.31 & 3 & 31.10 & .60 & .62 & .00 \\
\hline Cinsiyet * Bölüm & 128.11 & 3 & 42.70 & .82 & .48 & .01 \\
\hline Hata & 24419.02 & 468 & 52.18 & & & \\
\hline Toplam & 374777.00 & 476 & & & & \\
\hline $\begin{array}{l}\text { Düzeltilmiş } \\
\text { Toplam }\end{array}$ & 24796.64 & 475 & & & & \\
\hline
\end{tabular}

a. $R^{2}=.02$ (Düzeltilmiş $R^{2}=.00$ )

Tablo 5

Değişkenlere İlişkin Betimleyici İstatistikler

\begin{tabular}{lccccc}
\hline Değişkenler & $N$ & En düşük & En yüksek & 0 & Ss \\
\hline GNO & 476 & 1.52 & 3.77 & 2.77 & 0.41 \\
Derin Yaklaşım & 476 & 12.00 & 50.00 & 31.00 & 6.36 \\
Yüzeysel Yaklaşım & 476 & 10.00 & 49.00 & 27.12 & 7.23 \\
\hline
\end{tabular}

Regresyon analizinin varsayımları test edilmiş ve tolerance değerinin .10'dan büyük (.85), VIF değerinin 10'dan küçük (1.18) olduğu, koşul indeksinin 30'un altında (1.00 ile 16.73 arası) olması sebebi ile çoklu bağlantı probleminin olmadığı söylenebilir (Field, 2005). Diğer taraftan Durbin-Watson katsayısının 2'den küçük olması sebebi ile (1.85) artık değerler arasında ilişki olmadığı anlaşılmıştır. Bu sonuçlara dayalı olarak veri setinin regresyon analizine uygun olduğu söylenebilir. Katılımcıların ders çalışma yaklaşımının akademik başarısının anlamlı bir yordayıcısı olup olmadığını tespit etmek için yapılan çoklu regresyon analizi sonuçları Tablo $6^{\prime}$ da gösterilmiştir. Analiz sonuçları $(F(2,473)=26.33, p<.01)$ kurulan regresyon modelinin genel olarak anlamlı olduğunu ve akademik başarının yordanmasına ilişkin regrasyon eşitliğinin $\quad$ GNO $=2.92-01 Y Y+01 D Y$ şeklinde olduğunu göstermektedir.

Regresyon analizi, DY ve YY puanlarının GNO'nun anlamlı birer yordayıcısı olduğunu göstermektedir $\left(\beta_{D Y}=.12, \beta_{Y Y}=-.25\right)$. DY puanlarının GNO' yu pozitif, YY puanlarının ise negatif yönde yordadığı, GNO'da gözlenen değişkenliğin \% 10'unun bu iki değişken tarafından açıklandığı tespit edilmiştir $\left(R^{2}=10\right)$. YY puanlarının DY puanlarından daha güçlü bir yordayıcı olduğu anlaşılmaktadır. 
Tablo 6

DY ve YY Puanlarının GNO'yu Yordanmasına İlişkin Çoklu Regresyon Analizi Sonuçları

\begin{tabular}{lccccc}
\hline Model & B. Hata & Beta & $t$ & $P$ \\
\hline (Sabit) & 2.92 & .14 & & 20.60 & $.00^{* *}$ \\
DY & .01 & .00 & .12 & 2.50 & $.01^{*}$ \\
YY & -.01 & .00 & -.25 & -5.29 & $.00^{* *}$ \\
\hline$R: .32$ & $R^{2}: 10 F_{2,473:} 26.33, p<.01$ & & ${ }^{*} \mathrm{p}<.05$ & ${ }^{* *} \mathrm{p}<.01$
\end{tabular}

Tartışma, Sonuç ve Öneriler

Katılımcıların kayıtlı olduğu lisans programına göre derin yaklaşım puanları anlamlı bir farklılık gösterirken cinsiyet değişkenine göre anlamlı bir farklılık göstermemektedir. SÖ programına kayıtlı olan öğrencilerin derin yaklaşım puanlarının PDR ve İM programına kayıtlı öğrencilerin derin yaklaşım puanlarından daha yüksektir. Cinsiyet ve kayıtlı olunan program değişkeni katılımcıların yüzeysel yaklaşım puanlarında anlamlı bir farklılık oluşturmamaktadır.

Bu çalışmadan elde edilen bulguların, öğrenme yaklaşımının cinsiyete göre değişmediğine ilişkin ilgili literatürde (Ellez ve Sezgin, 2002; Ünal-Çoban ve Ergin, 2008; Sezgin-Selçuk vd., 2007; Yıldız, 2010; Zhang, 2000) elde edilen bazı sonuçlarla benzerlik gösterdiği anlaşılmaktadır. Bulgular, derin yaklaşım puanlarının cinsiyete göre değişmediğine iliş̧in araştırma sonuçları ile de tutarlıdır (Çuhadar vd., 2013; Dönmez vd., 2016; Ozan vd., 2012). Derin öğrenme yaklaşımını daha çok kız (Beşoluk ve Önder, 2010; Biggs, 1987; Dönmez vd., 2016; Ozan vd., 2012) veya erkek (Miller vd., 1990) öğrencilerin tercih ettiğine ilişkin araştırma bulgularından farklıdır.

Kayıtlı olunan program değişkeni derin yaklaşım puanları üzerinde düşük düzeyde bir etkiye sahiptir. Bulunan bu sonuç, ders çalışma yaklaşımı puanlarının öğrenim görülen bölüme göre değişmediğine ilişkin bulunan sonuçların yüzeysel yaklaşımla ilgili bölümü benzerlik gösterirken, derin yaklaşım puanlarına ilişkin sonuçlardan farklıdır (Karahan, 2017; Olpak ve Korucu, 2014). Bölüm değişkenine ilişkin bu bulgular, öğrencilerin derin yaklaşım puanlarının kayıtlı olduğu programa göre değiştiğine, yüzeysel yaklaşım puanlarının anlamlı bir farklılık göstermediğine ilişkin bulgularla benzerlik göstermektedir (Ekinci, 2009).

Nitelikli bir öğretimin derin yaklaşımı teşvik etmesi, yüzeysel yaklaşım alışkanlıklarını ise silmesi beklenir. Çünkü derin yaklaşım öğrenmeye, yüzeysel yaklaşım ise yüksek not veya geçer not almaya odaklanır. Bu araştırmada elde edilen bulgular, bu beklentiyi karşılamaktadır. Araştırma bulguları, yurt dışında yapılan bazı araştırma sonuçları ile benzerlik göstermektedir (Byrne vd., 2002; Gow, Kember ve Cooper, 1994; Janeiro, Duarte, Araújo ve Gomes, 2017; Liu vd., 2015; Sæle vd., 2017). Ayrıca elde edilen bu sonuç, yurt içinde yapılan bazı araştırma sonuçları ile de benzerlik göstermektedir (Çetin, 2016; Olpak ve Korucu 2014). Derin öğrenme yaklaşımının yabancı dil olarak İngilizce öğrenme başarısının olumlu etkilediğine (Alahdadi ve Ghanizadeh, 2017), derin öğrenen lisansüstü öğrencilerin meslektaşlarından daha iyi akademik sonuçlara sahip olduğuna ilişkin çalışma sonuçları (Akram vd., 2018) ile de benzerlik göstermektedir. Yüzeysel yaklaşım akademik başarıyı artırmanın kolay bir yolu olarak görülebilir. Ancak bu araştırma sonuçları, yüzeysel yaklaşımın bu amaca katkı sağlamadığını göstermektedir. 
Öğretim elemanlarının öğrencileri not almaya değil, öğrenmeye ikna etmeleri öğrencilerin derin yaklaşıma ilişkin motivasyon ve stratejileri benimseyip uygulamasına katkı sağlayabilir. Öğrenme olduğu takdirde bunun akademik başarıya da mutlaka yansıyacağı hususunda öğrencilerin bilgilendirilmesi önemli olabilir.

\section{Kaynakça}

Akbaba, S. (2006). Psikolojik danışma ve sınıf ortamlarında öğrenme psikolojisi (3. Baskı), Ankara: Aydan Matbaacilık.

Akram, N., Khan, N., Ameen, M., Mahmood, S., Shamim, K., Amin, M., and Rana, Q. U. A. (2018). Morningness-eveningness preferences, learning approach and academic achievement of undergraduate medical students. Chronobiology International, 15, 1-7. https://doi.org/10.1080/07420528.2018.1474473

Alahdadi, S., and Ghanizadeh, A. (2017). The dynamic interplay among efl learners' ambiguity tolerance, adaptability, cultural intelligence, learning approach, and language achievement. Iranian Journal of Language Teaching Research, 5(1), 3750.

Bandura, A. (1986). Social foundations of thought and action: A social cognitive theory. Englewood Cliffs, NJ, US: Prentice-Hall.

Beşoluk, Ş.ve Önder, İ. (2010). Öğretmen adaylarının öğrenme yaklaşımları, öğrenme stilleri ve eleştirel düşünme eğilimlerinin incelenmesi. İlköğretim Online, 9(2), 679-693.

Biggs, J. (1999). What the student does: teaching for enhanced learning. Higher Education Research and Development, 18 (1), 57-75. https:// doi.org/10.1080/0729436990180105

Biggs, J. B. (1987). Student approaches to learning and studying. Research Monograph. Melbourne: Australian Council for Educational Research, Radford House, Frederick St., Hawthorn 3122, Australia.

Biggs, J., Kember, D. and Leung, D. Y. P. (2001). The revised two-factor study process questionnaire: R-SPQ-2F. British Journal of Educational Psychology, 71(1), 133149. https:/ / doi.org/10.1348/000709901158433

Byrne, M.,Flood, B. and Willis, P. (2002). The relationship between learning approaches and learning outcomes: a study of Irish accounting students. Accounting education, 11(1), 27-42. https:/ / doi.org/10.1080/09639280210153254

Cohen, J. (1988). Statistical power analysis for the behavioral sciences (2nd ed.). Hillsdale, NJ: Erlbaum.

Çetin, B. (2016). Approaches to learning and age in predicting college students' academic achievement. Journal of College Teaching and Learning (Online), 13(1), 21-28. https:// doi.org/10.19030/tlc.v13i1.9568

Çuhadar, C., Gündüz, Ş. ve Tanyeri, T. (2013). Bilgisayar ve öğretim teknolojileri bölümü öğrencilerinin ders çalışma yaklaşımlarının ve akademik öz-yeterlik alg1larının incelenmesi. Mersin Üniversitesi Eğitim Fakültesi Dergisi, 9(1), 251259.

Dönmez, C., Yazıcı, K. ve Demirez, G. M. (2016). Sosyal bilgiler öğretmen adaylarının ders çalışma yaklaşımlarının incelenmesi. International Online Journal of Educational Sciences, 8(2), 227-239. 
Durmuşçelebi, M. (2013). Öğretmen yetiştiren kurumlarda öğrenci başarısını etkileyen bazı değişkenlerin incelenmesi (Erciyes Üniversitesi Örneği). Ĕ̆itim ve Bilim, 38(168), 373-385.

Ekinci, N. (2009). Üniversite öğrencilerinin öğrenme yaklaşımları. Eğitim ve Bilim, 34(151), 74-88.

Ellez, A. M. ve Sezgin, G. (2002). Öğretmen adaylarının öğrenme yaklaşımları. Orta Doğu Teknik Üniversitesi V. Ulusal Fen Bilimleri ve Matematik Eğitimi Kongresi, Ankara.

Entwistle, N., ve McCune, V. (2004). The conceptual bases of study strategy inventories. Educational Psychology Review, 16(4), 325-345. https:/ / doi.org/10.1007/s10648-004-0003-0

Field, A. (2005). Discovering stasitics using SPSS (Second Ed.). London: Sage Publication.

Gow, L.,Kember, D. and Cooper, B. (1994). The teaching context and approaches to study of accountancy students. Issues in Accounting Education, 9(1), 118-141.

Janeiro, I. N., Duarte, A. M., Araújo, A. M. and Gomes, A. I. (2017). Time perspective, approaches to learning, and academic achievement in secondary students. Learning and Individual Differences, 55, 61-68. https:/ / doi.org/10.1016/j.lindif.2017.03.007

Karahan, B. Ü. (2017). Türkçe öğretmenliği bölümü öğrencileri ile Türk dili ve edebiyatı bölümü öğrencilerinin ders çalışma yaklaşımlarının karşılaştırılması. Insan ve Toplum Bilimleri Araştırmalarn Dergisi, 6(5), 3316-3325.

Karagöz, Y. (2016). SPSS ve AMOS 23 Uygulamalı istatistiksel analizler. Ankara: Nobel Yayınevi.

Kilmen, S. (2015). Ĕ̆itim araştırmacıları için SPSS uygulamal istatistik. Ankara: Edge Akademi.

Liu, E. S., Carmen, J. Y. and Yeung, D. Y. (2015). Effects of approach to learning and self-perceived overall competence on academic performance of university students. Learning and Individual Differences, 39, 199-204. https:/ / doi.org/10.1016/j.lindif.2015.03.004

Miller, C. D.,Finley, J.and McKinley, D. L. (1990). Learning approaches and motives: Male and female differences and implications for learning assistance programs. Journal of College Student Development, 31(2), 147-154.

Olpak, Y. Z. ve Korucu, A. T. (2014). Öğrencilerin ders çalışma yaklaşımlarının farklı değişkenler açısından incelenmesi. Ahi Evran Üniversitesi Kırşehir Eğitim Fakültesi Dergisi, 15(1), 333-347.

Ozan, C., Köse, E., ve Gündoğdu, K. (2012). Okul öncesi ve sinıf öğretmenliği öğrencilerinin öğrenme yaklaşımlarının incelenmesi. Ĕ̆itim Bilimleri Araştırmaları Dergisi, 2(2), 75-92.

Sæle, R. G., Dahl, T. I., Sørlie, T. and Friborg, O. (2017). Relationships between learning approach, procrastination and academic achievement amongst firstyear university students. Higher Education, 74(5), 757-774. https: / / doi.org/10.1007/s10734-016-0075-z

Sezgin-Selçuk, G., Çalışkan, S., ve Erol, M. (2007). Fizik öğretmen adaylarının öğrenme yaklaşımlarının değerlendirilmesi. Gazi Ĕ̆itim Fakültesi Dergisi, 27(2), 25-41. 
Ünal-Çoban, G. ve Ergin, Ö. (2008). İlköğretim öğrencilerinin feni öğrenme yaklaşımları. Uludă̆ Üniversitesi Ĕ̆itim Fakültesi Dergisi, 21(2), 271293.

Yaşar, M. (2016). Öğretmen adaylarının akademik başarısını etkilediği düşünülen özelliklerin sıralama yargıları yöntemine dayalı ölçeklenmesi. Pamukkale Üniversitesi Eğitim Fakültesi Dergisi, 40(40), 274-288.

Yıldız, H. (2010). Öğretmen adaylarının sahip oldukları öğrenme stilleri ve öğrenme yaklaşımları arasındaki ilişki. Birinci Ulusal Eğitim Programı ve Öğretimi Kongresi, Balıkesir.

Yılmaz, M. B., ve Orhan, F. (2011). Ders çalışma yaklaşımı ölçeğinin Türkçe formunun geçerlik ve güvenirlik çalışması. Eğitim ve Bilim, 36(159), 69-83.

Zhang, L. (2000). University students' learning approaches in three cultures: an Investigation of Bigg's 3p model. The Journal of Psychology, 134 (1), 37-55. https:// doi.org/10.1080/00223980009600847

\section{Summary}

\section{Introduction}

The study approach is one of the factors that affect academic achievement. There are few studies that show what factors influence the study approach and how the study approach affects academic achievement. It should be noted that the variables of the study approaches of the pre-service teachers and the effect on the academic achievement will contribute to the planning of the learning process and the implementation process.

The aim of this study is to determine whether there is a significant difference between the study approaches of education faculty students according to their gender and major and find out whether the student's study approach is a meaningful predictor of the academic achievement or not.

\section{Method}

The data in this survey study were collected from 476 students in the education faculty departments in the 2017-2018 academic year. The participants registered in four different teacher training departments consisted of 161 male and 315 female students.

The data related to the General Achievement Scores (GAS) of the participants and gender were collected using a personal information form developed by the researchers. To calculate the deep and superficial approach scores, the Studying Approaches Scale (SAS) developed by Biggs, Kember and Leung (2001), adapted into Turkish by Y1lmaz and Orhan (2011), was administered. 10 items of the SAS, which consisted of totally 20 items, was related to measuring the deep approach, while 10 were related with the superficial aproach. The inner consistency coefficients calculated in this present study were .77 for deep approach and .78 for superficial approach.

The factorial ANOVA was conducted to investigate whether there was a meaningful difference between the study approaches of the students according to their gender and teacher training department they belonged to; a multiple regression analysis was used to determine whether their study approaches were significant 
predictors of their academic achievements. The enter method, which is the standard method in regression analysis, was used. The variables of DA and SA were included in the model, and the common effect of the both independent variables on GAS were examined.

\section{Results}

According to the results, it was found that the department variable had a meaningful difference on the scores of the deep approach; on the other hand, the gender variable did not create any meaningful differences. It was understood that the department variable had a low level of influence on deep approach scores. It was found that the common effect of the gender and major on the deep approach scores were at the significance limits and had low level of common influence. It was understood that the significant difference based on Turkey test were between the students registered in Primary School Education department and those in Psychological Counselling and Guidance and Elementary Mathematics Education departments.

The results of factorial ANOVA for independent groups of participants' gender and superficial approach scores according to the department showed that gender and department variables did not make a meaningful difference on superficial approach scores.

The correlation between the participants' SAS, deep approach and superficial approach scores demonstrated that there was a positive meaningful correlation between their SAS and deep approach scores, and negative meaningful correlation between the deep and superficial approach scores. A negative correlation was found between deep and superficial approach scores.

A multiple regression analysis was carried out to investigate whether study approaches of the participants were a significant predictor of the academic achievement, and it suggested that DA and SA scores were a significant predictor of SAS. It was determined that the DA scores predicted the SAS positively, and SA negatively, $10 \%$ of the variability observed in SAS were explained by these two variables. It was understood that the SA scores were more powerful predictors compared with the DA scores.

\section{Discussion}

While the deep approach scores of the participants across departments demonstrated a significant difference, they did not demonstrate any significant differences across the genders. The deep approach scores of the students, who were in Primary School Education department, were higher than the scores of those, who were in Psychological Counselling and Guidance and Elementary Mathematics Education departments. Gender and the department variables do not create a significant difference in the superficial approach scores of the participants. It is understood that the findings, related to whether the learning approach show difference according to the gender variable, gathered in this study, had similarities with the results in the relevant literature (Ellez and Sezgin, 2002; Sezgin-Selçuk et al., 2007; Ünal-Çoban and Ergin, 2008; Y1ld1z, 2010; Zhang, 2000). The findings are also consistent with the results of research on whether deep approach scores do not differ according to gender (Çuhadar et al., 2013; Dönmez et al., 2016; Ozan et al., 2012). The findings of this research, related to whether the deep learning approach is more frequently 
preferred by females (Beşoluk and Önder, 2010; Biggs, 1987; Dönmez et al., 2016; Ozan et al., 2012), or males (Miller et al., 1990) are different from the findings of the studies in the literature.

The variable of the department has a low level of influence on the deep approach scores. This result is different from the results related to the deep approach scores, while the results of the study findings related to the superficial approach, whether the scores of studying approach change, show similarity (Karahan, 2017; Olpak and Korucu, 2014).

These findings for the department variable are similar to the findings that the students did not have a significant difference in the superficial approach scores compared to the department in which the deep approach scores of the students were recorded (Ekinci, 2009).

It is expected that a qualified teaching should encourage a deep approach, and erase the superficial approach habits. The deep approach focuses on learning, while the superficial approach focuses on getting high grades or passing the class. The findings obtained in this research meet the relevant expectations. Some of the findings from this study are similar to those of earlier research results conducted abroad (Byrne et al., 2002; Gow et al., 1994; Janeiro et al., 2017; Liu et al., 2015; Sæle et al., 2017). In addition, they are also similar to some domestic research results (Çetin, 2016; Olpak and Korucu 2014). The study results related to that the deep learning approach affect the English learning achievement positively as a foreign language (Alahdadi ve Ghanizadeh, 2017), demonstrate similarity with the research results related to the deep learner graduate students had better academic results compared with their colleagues (Akram et al., 2018). The superficial approach can be seen as an easy way to improve academic achievement. However, the results of the research show that the superficial approach does not contribute to this aim.

Instructors, convincing the students to learn, not to get marks, can contribute to their adopting and implementing motivation and strategies for deep approaching. If learning occurs, it may be significant to inform students about this and it absolutely be reflected in academic achievement.

\section{Authors' Biodata / Yazar Bilgileri}

Hüseyin Hüsnü BAHAR Erzincan Üniversitesi Eğitim Fakültesi'nde Doçent Doktor olarak görev yapmaktadır. Eğitim programları ve öğretimi alanında çalışmaları bulunmaktadir.

Hüseyin Hüsnü BAHAR is an associate professor at Erzincan University, Faculty of Education. He has studies on curriculum and teaching.

Muzaffer OKUR Erzincan Üniversitesi Eğitim Fakültesi'nde Doçent Doktor olarak görev yapmaktadır. Matematik eğitimi ve öğretimi alanında çalışmaları bulunmaktadir.

Muzaffer Okur is an associate professor at Erzincan University, Faculty of Education. He has studies on mathematics education and teaching. 